\title{
Manejo de ferimento extenso em terço superior face: relato de caso clínico
}

\author{
Management of extensive injury in the upper third face: clinical case report \\ Manejo de lesiones extensas en la tercera cara superior: reporte de caso clínico
}

\section{Resumo}

As lesões faciais de tecido mole podem ser consideradas como um desafio de estudo para as profissões que trabalham com a reabilitação estética e funcional dessa área, como o cirurgião bucomaxilofacial. Esses ferimentos podem assumir um papel de destaque no atendimento aos pacientes traumatizados devido ao seu potencial de comprometer a vida do indivíduo, pois, quando mal manejados, deixam sequelas que apresentam repercussões emocionais, funcionais e possíveis deformidades permanentes. Paciente do sexo masculino, 33 anos de idade, atendido no Hospital da Restauração Governador Paulo Guerra, Recife, Pernambuco, com história de queda de portão de ferro sobre a cabeça (acidente de trabalho), cursando de traumatismo cranioencefálico leve e ferimento extenso em região de face e couro cabeludo. O tratamento estabelecido foi a antissepsia com digluconato de clorexidina $2 \%$ na região, irrigação copiosa com soro fisiológico estéril $0,9 \%$ e sutura em planos. As lesões de tecido mole em face têm potencial de comprometer a vida do indivíduo, podendo ocasionar sequelas que apresentam repercussões emocionais, funcionais e possíveis deformidades permanentes. O diagnóstico e manejo adequado por parte da equipe de cirurgia e traumatologia bucomaxilofacial é de suma importância.

Palavras-chave: Ferimentos e lesões; Suturas; Traumatismos faciais. 


\begin{abstract}
Facial soft tissue injuries can be considered a study challenge for professions that work with aesthetic and functional rehabilitation in this area, such as maxillofacial surgeons. These injuries can play a prominent role in the care of traumatized patients due to their potential to compromise the individual's life, as, when badly handled, they leave sequelae that present emotional and functional repercussions and possible permanent deformities. male patient, 33 years old, treated at the Hospital da Restauração Governador Paulo Guerra, Recife, Pernambuco, with a history of falling an iron gate on his head (work accident), attending a mild traumatic brain injury and extensive wound in the face and scalp. The established treatment was antisepsis with $2 \%$ chlorhexidine gluconate in the region, copious irrigation with $0.9 \%$ sterile saline and suturing in planes. Soft tissue lesions on the face have the potential to compromise the individual's life and may cause sequelae that have emotional and functional repercussions and possible permanent deformities. The diagnosis and proper management by the maxillofacial surgery and traumatology team is of paramount importance.
\end{abstract}

Keywords: Wounds and injuries; Sutures; Facial injuries.

\title{
Resumen
}

Las lesiones de tejidos blandos faciales pueden considerarse um desafío de estudio para las profesiones que trabajan com la rehabilitación estética y funcional en esta área, como los cirujanos maxilofaciales. Estas lesiones pueden jugar un papel destacado en el cuidado de los pacientes traumatizados por su potencial de comprometer la vida del individuo, ya que, mal manejadas, dejan secuelas que presentan repercusiones emocionales y funcionales y posibles deformidades permanentes. Paciente masculino, 33 años, atendido en el Hospital da Restauração Governador Paulo Guerra, Recife, Pernambuco, con antecedente de caída de una reja de hierro en la cabeza (accidente de trabajo), atendiendo una lesión cerebral traumática leve y herida extensa. En la cara y el cuero cabelludo. El tratamento estabelecido fue antisepsia con gluconato de clorhexidina al $2 \%$ en la región, irrigación abundante con suero salino estéril al $0,9 \%$ y sutura en planos. Las lesiones de tejidos blandos en la cara tienen el potencial de comprometer la vida del individuo y pueden causar secuelas que tienen repercusiones emocionales y funcionales y posibles deformidades permanentes. El diagnóstico y manejo adecuado por parte del equipo de cirugía y traumatologia maxilofacial es de suma importancia.

Palabras clave: Heridas y lesiones; Suturas; Traumatismos faciales.

\section{Introdução}

As lesões faciais que envolvem os tecidos moles possuem epidemiologia variável de acordo com a população estudada, podendo acontecer devido a acidentes automobilísticos, quedas, violências, e realização de atividades recreativas, como andar de bicicleta (Hong et al, 2000; Vieira et al, 2013; Truong, 2017; Ghosh, Gopalkrishnan, 2018; Barbosa et al, 2020).

Esses ferimentos podem assumir um papel de destaque no atendimento aos pacientes traumatizados devido ao seu potencial de comprometer a vida do indivíduo, pois, quando mal manejados, deixam sequelas que apresentam repercussões emocionais, funcionais e possíveis deformidades permanentes (Vieira et al, 2013; Cavalcante et al, 2020).

A pele da face possui projeção anterior corporal, sendo extremamente exposta a agressões, que, ao ser comprimida entre os ossos e as forças de agressão externa, podem sofrer inúmeras lesões que deixam sequelas importantes (Vieira et al, 2013; Aguiar et al, 2020). O aparecimento dessas lesões está relacionado à ação de um agente traumático superficial ou profundo, que pode apresentar diversos níveis de complexidade, que irá guiar a melhor terapêutica de acordo com a extensão, profundidade, agente etiológico, grau de contaminação e tempo de trauma (Cavalcante et al, 2020).

Comumente as lesões de tecidos moles podem apresentar grandes dimensões e expor periósteo intacto ou defeituoso, tornando mais suscetível a infecções graves e suprimento sanguíneo insuficiente (Mussaini et al, 2007; Chen et al, 2017). Elas também podem ocorrer de forma única ou associadas a alguma outra lesão e raramente são fatais (Truong,2017; Ghosh, Gopalkrishnan, 2018).

O trauma maxilofacial também vem sendo apontado como um problema social e econômico relevante por causar perda de produtividade, custos significativos de tratamento, danos materiais e dificuldade de reintegração da vítima à sociedade (Ghosh, Gopalkrishnan, 2018). Suas lesões têm demonstrado impacto relevante devido a essa região possuir uma grande importância comunicativa e sensorial, concentrando nela a visão, audição, olfato e paladar (Singh,2012). 
As lesões faciais de tecido mole são um desafiador foco de estudo para as profissõesque trabalham com a reabilitação estética e funcional dessa área, como o cirurgião bucomaxilofacial, e podem ter graves consequências, como a perda de sensibilidade (Silva et al, 2011; Pinto et al 2018; Aguiar et al, 2020). Diante disso, o presente trabalho tem como objetivo relatar um caso de ferimento corto-contuso extenso em terço superior da face, bem como a conduta empregada em um serviço de cirurgia e traumatologia bucomaxilofacial de emergência na cidade do Recife.

\section{Metodologia}

O estudo de caso é uma descrição e análise, a mais detalhada possível, de um caso que apresente alguma particularidade que o torna especial, trazendo riqueza de dados e informações que contribuem com o saber na área abordada (Pereira et al, 2018).

O presente ensaio é um estudo intervencional descritivo e qualitativo de relato de caso, o qual possui a autorização do paciente por meio do Termo de Consentimento Livre e Esclarecido (TCLE), elaborado em linguagem acessível à compreensão do paciente relatado, demonstrando o destino das informações recolhidas do paciente, bem como os benefícios e riscos relacionados à sua participação que foi assinada após o mesmo dar entrada no Hospital. Além disso, foi realizada uma revisão da literatura por meio de busca de artigos científicos, relatos de casos, revisões sistemáticas e meta-análises.

\section{Relato de Caso}

Paciente do sexo masculino, 33 anos de idade, atendido no Hospital da Restauração Governador Paulo Guerra, Recife, Pernambuco, com história de queda de portão de ferro sobre a cabeça (acidente de trabalho) há cerca de uma hora, cursando de traumatismo cranioencefálico leve e ferimento extenso em região de face e couro cabeludo (Figura 1).

Figura 1: Vista sagital e transversal do paciente no atendimento inicial.

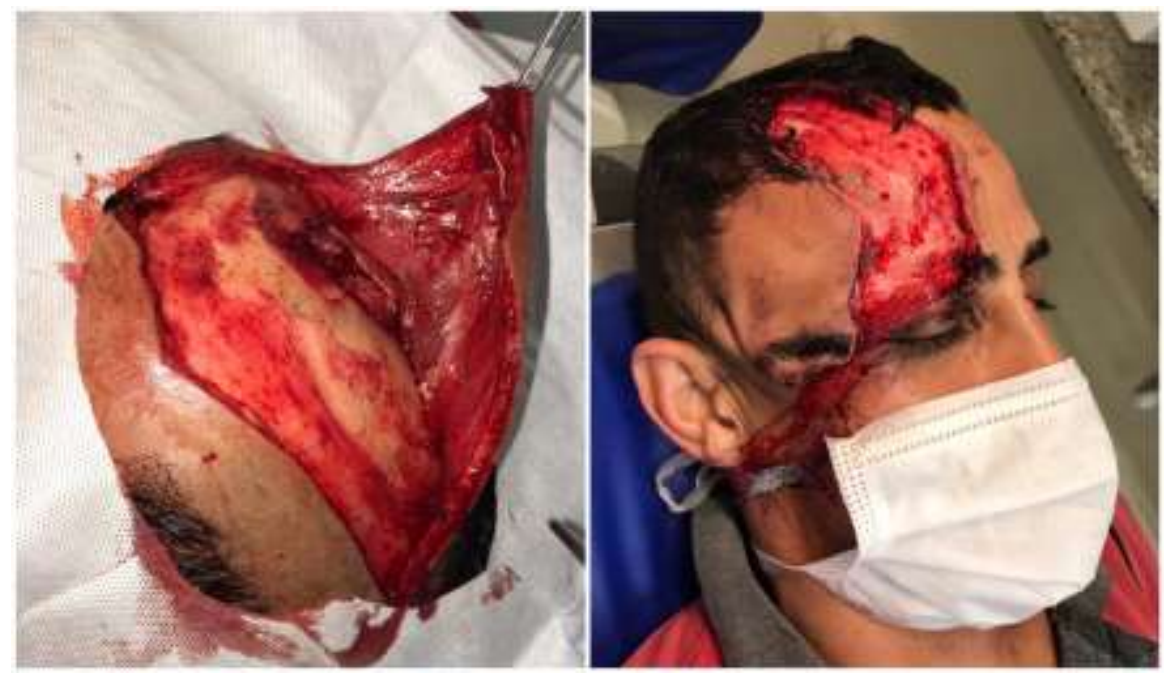

Fonte: Autores

Após a avaliação inicial efetuada pela equipe de neurocirurgia da emergência, o mesmo foi considerado sem indicação neurocirúrgica. Dessa forma, foi liberado pela equipe de neurocirurgia para a realização do tratamento com a equipe de cirurgia e traumatologia bucomaxilofacial (CTBMF).

Ao exame físico foi observado ferimento corto-contuso extenso, com exposição óssea, em região de fronte com extensão para área do couro cabeludo. Acuidade visual e motricidade ocular preservados, ossos da face firmes à palpação, boa abertura bucal e oclusão estável, ao exame de tomografia computadorizada, não sugeriu fraturas em ossos da face. 
Diante da ausência de fraturas dos ossos da face, o paciente foi submetido a síntese dos tecidos moles. Devido ao pouco tempo em que ocorreu a última alimentação, optou-se por fazer o procedimento por meio da anestesia local com vasoconstrictor (lidocaína $2 \%$ com epinefrina 1:100.000). Nesse sentido, foi realizada a tricotomia do couro cabeludo, seguida de infiltração do anestésico e assepsia com gliconato de clorexidina a $2 \%$, irrigação copiosa com soro fisiológico estéril a $0,9 \%$ e colocação do campo operatório.

$\mathrm{Na}$ região de pálpebra direita e fronte foi utilizada a sutura em planos, com fio de sutura reabsorvível (Poliglecaprone 25- Bioline, 4.0) para pontos internos com objetivo de aproximação da musculatura e síntese de tecido subcutâneo e fio de sutura não reabsorvível (Nylon- Shalon, 5.0) para os pontos externos, a nível de pele. Já na região de couro cabeludo, foi efetuada apenas pontos externos com o fio de sutura não reabsorvível (Nylon- Shalon, 3.0). Ao concluir a sutura da lesão, foi efetuada a instalação de dreno a vácuo (Figura 2).

Figura 2: Vista tranversal após a instalção do dreno a vácuo.

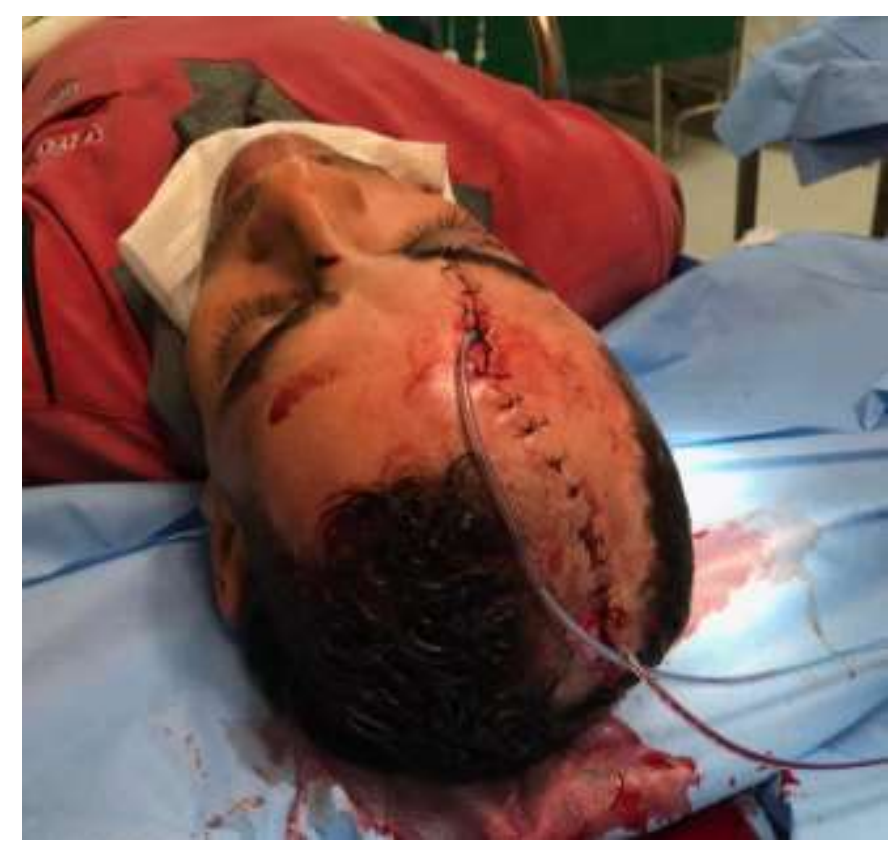

Source: Authors.

Após a finalização da instalação do dreno a vácuo, o paciente foi submetido a administração de soro antitetânico, vacina antitetânica e ao uso de antibióticos (cefalotina $1 \mathrm{~g}$ a cada 6 horas e metronidazol 500mg a cada 8 horas) e corticosteróide (dexametasona $4 \mathrm{mg}$ a cada 8 horas) por via endovenosa em ambiente hospitalar.

Devido à saída de débito sanguinolento pelo dreno ter sido menor que $10 \mathrm{ml} \mathrm{em} 24$ horas, foi optado pela sua remoção, seguido de alta hospitalar. Após 23 dias, o paciente retornou para acompanhamento ambulatorial apresentando cicatrizes perceptíveis, bem posicionadas e com bom resultado estético. Além disso, também foi constatada parestesia e disestesia em fronte direita, mobilidade local preservada e ausência de diplopia, visão embaçada ou déficit motor ocular (Figura 3). 
Figura 3: Vista sagital, coronal e tranversal após 23 dias do procedimento.

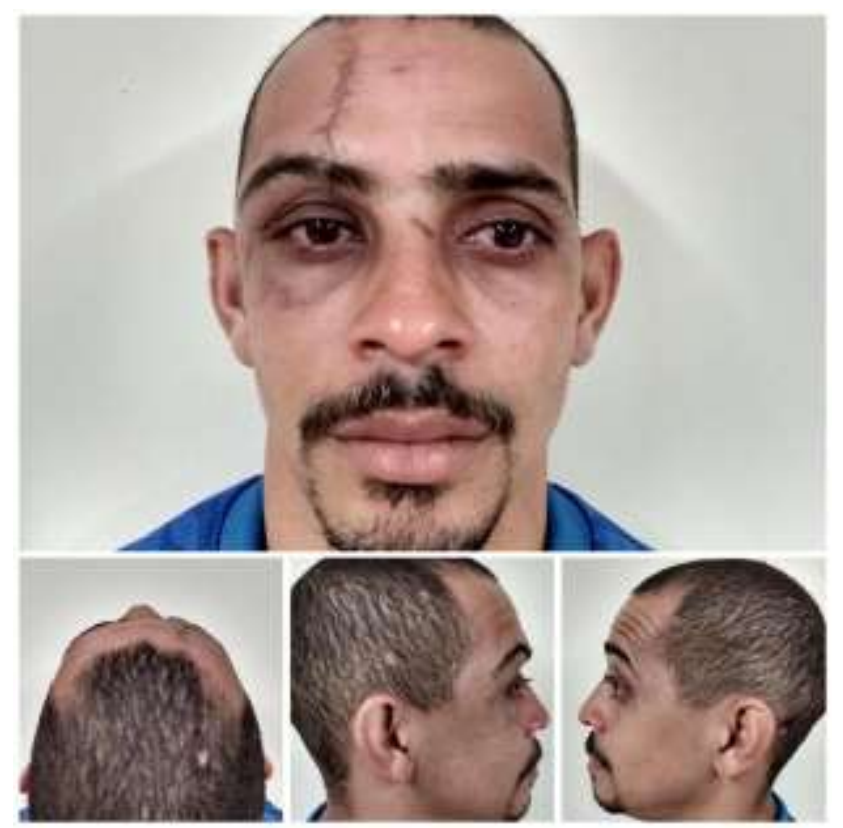

Source: Authors.

Decorridos 3 meses do procedimento o paciente foi reavaliado e foi constatada diminuição da parestesia e disestesia. Paciente encontra-se em acompanhamento ambulatorial sem intercorrências e sem alterações funcionais ou estéticas significativas (Figura 4).

Figura 4: Vista sagital e coronal após 3 meses do procedimento.
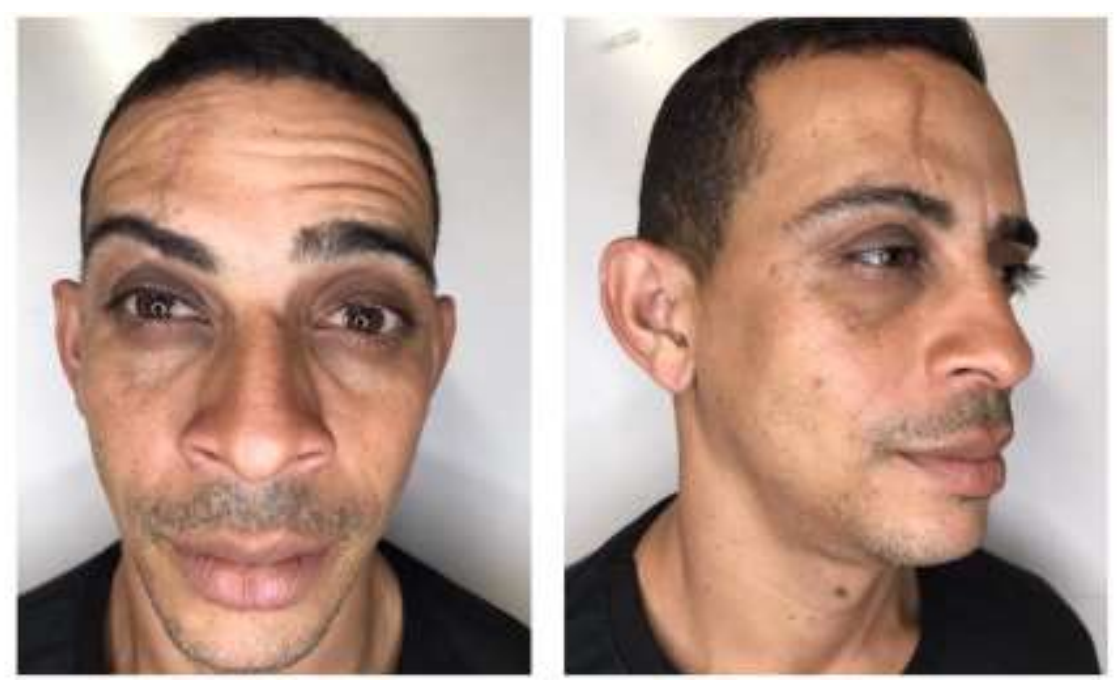

Source: Authors.

\section{Discussão}

De acordo com a Organização Mundial de Saúde (OMS), os traumas estão entre as principais causas de morte e morbidade no mundo (Silva, 2011). Dentre eles, o facial tem demonstrado um crescimento importante nas últimas décadas, estando associado ao aumento de acidentes automobilísticos devido à crescente urbanização e acesso aos meios de transporte (Troung, 2017; Cavalcante et al, 2020) 
O trauma de face apresenta predileção pelo sexo masculino, entre 21 e 30 anos e, em lesões de tecido mole, a fronte é o local de maior prevalência (Hussaini et al, 2007; Vieira et al, 2013; Ghosh, Gopalkrishnan, 2018). Neste caso, o perfil do paciente corresponde com o encontrado na literatura.

$\mathrm{O}$ trauma relatado foi provocado por um portão, que ao cair sobre a cabeça do paciente, ocasionou ferimento cortocontuso extenso. Segundo a dinâmica afirmada por Vanrell (2016), essa lesão é causada por instrumentos corto-contundentes, os quais aplicam sua energia sobre uma linha e massa, utilizando um mecanismo de pressão-esmagamento.

As lesões em pele podem ocasionar danos nos nervos relacionados à motricidade e sensibilidade da região, podendo causar alterações em suas funções (Nascimento et al, 2020; Aguiar et al, 2020). Neste caso, o paciente apresentou na primeira consulta de retorno, após 23 dias, parestesia e disestesia com melhora da queixa na segunda consulta, após 3 meses. Essa sintomatologia ocorreu devido ao provável acometimento dos ramos supraorbital e supratroclear.

Os ferimentos faciais podem ser tratados sob anestesia local ou geral. Assim como ocorreu nesse relato, a anestesia local é utilizada na maioria dos casos. O anestésico de primeira escolha é o cloridrato de lidocaína a $2 \%$ com epinefrina (vasoconstritor) na concentração de 1:100.000. O uso de vasoconstritores objetiva diminuir o sangramento, retardar a absorção e prolongar o efeito anestésico (Barbosa et al, 2020).

A descontaminação da ferida é um dos passos mais importantes no tratamento de lesões de tecido mole (Figueiró, 2016). Deve-se realizar o debridamento de tecidos desvitalizados, remoção de corpos estranhos, irrigação copiosa dos ferimentos, reposicionamento e sutura dos tecidos (Santos et al., 2007; Figueiró, 2016; Diógenes et al., 2021). Neste relato, para descontaminação das lesões, foi utilizado Digluconato de Clorexidina 2\% e irrigação copiosa com solução salina $0,9 \%$ para a assepsia da região.

Para melhor prognóstico funcional e estético em feridas de face, cabeça e pescoço, o ideal é o fechamento primário das lesões. (Mathur et al., 2011; Rui-feng et al, 2013). Em suturas de face deve-se utilizar fios que promovam boa aproximação das bordas da ferida e menores marcas na pele. Os tecidos são aproximados por planos, impedindo a formação de espaço morto, minimizando as tensões e restabelecendo a posição original das camadas (Singer et al, 2005).

A terapia de pressão negativa por meio dreno a vácuo foi utilizada no presente caso devido à grande extensão do ferimento e pela rica vascularização da região. Ela auxilia na remoção de fluido, diminuição da umidade, redução de bactérias, aumento da densidade de vasos e conteúdo de colágeno (Anghel; Kim, 2016; Chen et al, 2017). Normalmente, esse sistema é removido com 2 a 3 dias, tornando a ferida menos suscetível a contaminação (Anghel; Kim, 2016).

Para avaliar a necessidade de terapia antibiótica, é imprescindível a determinação da sua origem e extensão (Figueiró, 2016). Por se tratar de um paciente monitorado no hospital, foi optado pela antibioticoterapia endovenosa durante o período de internamento.

O tétano acidental é uma doença infecciosa aguda, prevenível por vacina, causada por esporos, que podem introduzirse em solução de continuidade de pele e mucosas (Dantas et al, 2013; Ohama et al, 2019). O status vacinal do indivíduo, a etiologia do trauma e o grau de contaminação do ferimento devem ser considerados na decisão clínica (Dantas et al, 2013). A dose de reforço da vacina antitetânica deve ser aplicada em casos de esquema vacinal completo (paciente que recebeu as 3 doses) quando a terceira dose foi aplicada há mais de 5 anos. Nos casos de imunização incompleta (menos de 3 doses) ou a falta de imunização prévia, deve-se, além de completar ou iniciar a vacinação do paciente, administrar soro antitetânico ou a imunoglobulina humana antitetânica (Dantas et al, 2013). Devido à incerteza sobre o estado vacinal do paciente, o protocolo adotado foi administrar a terapêutica de imunização incompleta.

\section{Conclusão}

As lesões de tecido mole em face possuem potencial de comprometer a vida do indivíduo, podendo ocasionar sequelas 
que apresentam repercussões emocionais, funcionais e possíveis deformidades permanentes. Cabe ao Cirurgião Bucomaxilofacial reconhecer, diagnosticar e aplicar a conduta adequada com foco na reabilitação funcional e estética do paciente.

Considerando o impacto dessas lesões, bem como a constante necessidade de atualização da literatura científica, fazse necessário mais estudos acerca do tema, a fim de otimizar a abordagem e melhorar o prognósticodesses pacientes.

\section{Referências}

Anghel, E. L. \& Kim, P. J. (2016) Negative-Pressure Wound Therapy: A Comprehensive Review of the Evidence. Wound Healing, 129S-137S.

Barbosa, L. M, Arruda, C. V. B, Fonseca, E. L. G, Pinto, P. S., Oliveira, L. M. L., Cunha, J. S., Carneiro, S. C. A. S \& Vasconcelos, B. C. E. (2020, junho). Tratamento de lesão extensa em face decorrente de trauma. Relato de caso. Brazilian Journal Of Health Review, Curitiba, 3 (3), 5321-5330.

Bonham, J. (2011). Comparison of suture types in the closure of scalp wounds. Emergency NURSE, 19(3), 34-39.

Cavalcante, M. B., Rocha, C. B. S., Uchôa, C. P., Marcelino, I. M. P, Siqueira, N. B \& Silva, E. D. O. Lesão De Tecido Mole Após Acidente Motociclístico. (2020, novembro) Odontol. Clín.-Cient., Recife, 19 (5), 408-411.

Chen, L., Li, G., Liu, S., Ma, X., Li, X., Su, Y. \&Guo, S. (2017). Comparison of Negative Pressure Wound Therapy and Conventional Therapy for Cranial Bone-exposed Wounds in Rabbits. Annals of Plastic Surgery, 74(4), 397-403.

Dantas, R. F., Dias, M. A. P., Filho, M. O. D., Ribeiro, E. D. \& Andrade, G. S. S. (2013, abril) Lesão de tecidos moles causada por arma branca - revisão de literatura. Rev. Odontol. Univ. Cid. São Paulo, 25(1), 40-6.

De Aguiar, J. F., \& Gomes, V. R., de Melo, M. C. S., Jorge M. J., Melo M. J. R. (2020). Manejo bucomaxilofacial de tecidos moles e duros após queda de bicicleta: relato de caso. Brazilian Journal of Oral and Maxillofacial Surgery, 20(3), 34-38.

Diógenes, C. C., Bezerra, F. H. V., da Silva, M. B., de Almeida, I. T., de Morais Neves, L. E., Teixeira, F. G., \& Maciel, F. A. C. (2021). Manejo de lesão extensa face decorrente de mordedura canina em paciente pediátrico: Relato de caso clínico. Research, Society and Development, 10(9), e546101918374e546101918374.

Figueiró, AP. (2016) Prevalência de injúrias em tecidos moles em pacientes atendidos em um centro especializado no tratamento de traumatismos dentários. RFO, Passo Fundo, 21(3), 401-6.

Ghosh, R. \& Gopalkrishnan, K. (2018). Facial Fractures. Journal of Craniofacial Surgery, 29(4), 334-340. 10.1097/scs.0000000000004269

Heitz, C., Louzada, G. P., Conci, R. A., Rodrigues, R. L., \& Fritscher, G. G. (2018) Reparo primário de uma fratura panfacial complexa por mordida de cachorro. Plast Reconstr Surg Glob Open. 6 (4): e1719.

Hogg, N. J., Stewart, T. C., Armstrong J. \& Girotti, M. J. (2000) Epidemiology of maxillofacial injuries at trauma hospitals in Ontario, Canada, between 1992 and 1997. J Trauma, 49,425-32. 10.1097/00005373-200009000-00007

Hussaini, H. M., Rahman, N. A., Rahman, R. A., Nor, G. M., AI Idrus, S. M. \& R. Ramli. (2007). Maxillofacial trauma with emphasison soft-tissue injuries in Malaysia. Int. J. Oral Maxillofac. Surg. 36, 97-801.

Mathur A., Ramesh K., \& Kumar G. A. (2011) Management of animal bite wounds on face: our experience. World Journal of Dentistry. 2(4):309-311.

Nascimento, R. S. N, Carneiro, L. A. C, Almeida, N. G, Lasso, D. M. M \& Souza, A. S. (2020, agosto) Tratamento De Fraturas Múltiplas Da Face Associadas A Ferimento Extenso: Relato De Caso. Revista Odontológica de Araçatuba, 41(1), 22-27.

Ohama, Victor Hideo, Bezerra, A. M., Castro, E. F \& Sprovieri, S. R. S. (2019, agosto). Tétano acidental em adultos: uma proposta de abordagem inicial. Arq Med HospFacCienc Med Santa Casa São Paulo, 64(2), 120-124.

Pereira A. S. et al. (2018). Metodologia da pesquisa científica. UFSM.

Pinto, P. S. (2018, junho) Manejo de ferimento extenso em terço médio da face. Rev. Cir. Traumato. Buco-Maxilo-Fac., 18(2), 53-57.

Rui-Feng C., Li-Song H., Ji-Bo Z., \& LiQiu W. (2013) Emergency treatment on facial laceration of dog bite wounds with immediate primary closure: a prospective randomized trial study. BMC Emergency Medicine, 13(Suppl 1): S2.

Sahni, V. (2017). Psychological Impact of Facial Trauma. Craniomaxillofacial Trauma \&Reconstruction, 11(01), 015-020. 10.1055/s-0037-1603464

Santos, T. S., Antunes, A. A., Carvalho, R. W. F., Avelar, R. F., Melo, R. E. V. A., \& Dourado, E. (2007) Perfil dos pacientes vítimas de mordeduras faciais: um estudo retrospectivo. RGO, Porto Alegre, 55(4), 369-73

Segundo, A. V. L., Gondim, D. G. A., \&Caubi, A. F. (2007). Tratamento dos ferimentos faciais. Rev. Cir. Traumatol. Buco-Maxilo-fac,7(1): 9 - 16.

Silva, J. J. L. (2011). Trauma facial: análise de 194 casos. Rev. Bras. Cir. Plást., 26(1), 37-41.

Singer A. J. et al. (2005). Single-layer versus double-layer closure of facial lacerations: a randomized controlled trial. Plast Reconstr Surg. 116(2)369-370. 10.1097/01.prs.0000172758.00088.81 
Research, Society and Development, v. 10, n. 11, e126101119422, 2021

(CC BY 4.0) | ISSN 2525-3409 | DOI: http://dx.doi.org/10.33448/rsd-v10i11.19422

Singh, V., Malkunje, L., Mohammad, S., Singh, N., Dhasmana, S. \& Das, S. K. (2012) The maxillofacial injuries: A study. National Journal of Maxillo facial Surgery, 3, 166-171.

Truong, T. A. (2017) Initial Assessment and Evaluation of Traumatic Facial Injuries. Seminars in Plastic Surgery, 31(2), 69-72.

Vanrell, J. P. (2016). Odontologia Legal e Antropologia Forense. (2a ed.), Guanabara Koogan.

Vieira, C. L., Araujo, D. C. C., Ribeiro, M. L. S \& Filho, J. R. L. (2013) Lesão de tecido mole em pacientes vítimas de trauma buco-maxilo-facial. Rev. cir. traumatol. buco-maxilo-fac., 13(1), 97-104. 